\title{
ALCEU

Histórias midiáticas ou midiatização da história das marcas? ${ }^{1}$

O caso da Nestlé no Brasil, envolvendo o naufrágio do Vapor Itagiba ${ }^{2}$

Media stories or mediatization of the brand history?

Nestlé's case in Brazil, involving the wreck of the Itagiba Steam

\section{Adriana G. Freitas e Eneus Trindade Barreto Filho}

\section{Introdução}

O presente artigo busca discutir o papel da memória e da história na lógica econômica e midiatizadora das organizações em processos de expansões globais, a partir do acontecimento do naufrágio do Vapor Itagiba no Brasil durante a Segunda Guerra Mundial, no que diz respeito às ações de institucionalização e promoção da marca Nestlé no Brasil. $\mathrm{O}$ artigo inicia-se apresentando um fato histórico, como acontecimento e os usos midiáticos dessa ocorrência em benefício da ação institucional e promoção da memória organizacional da marca Nestlé em sua ação de expansão no contexto brasileiro.

O texto finaliza ressaltando os aspectos teóricos e metodológicos para os estudos de midiatização das marcas na ação da construção das institucionalidades e das memórias organizacionais nas culturas, como possibilidade de estabelecer vínculos com os vários públicos das organizações em seus processos de expansão em vários mercados de consumo.

\section{O caso Nestlé e o naufrágio do Vapor Itagiba em 1942:}

Da tragédia para um acontecimento comunicacional

Estamos no dia 17 de agosto de 1942. Passava pela costa da Bahia o Itagiba, um vapor pertencente à Companhia Nacional de Navegação Costeira, que saíra do estado do Rio de Janeiro três dias antes. Seu destino era atracar no porto da capital de Pernambuco, na cidade de Recife. Essa embarcação havia feito escalas em Vitória e Salvador. Encontravam-se a bordo militares e

\footnotetext{
${ }^{1}$ Este trabalho é uma versão modificada do texto apresentado no IX Propesq PP - Encontro de Pesquisadores em Publicidade e Propaganda. De 23 a 25/05/2018. CRP/ECA/USP. GT 5 - Publicidade, tendências de mercado e consumo.

2 Itagiba (navio).https://pt.wikipedia.org/wiki/Navios brasileiros afundados na Segunda Guerra Mundial, acessado em 30/04/2019
} 
civis. Quando o navio passou nas proximidades do Farol do Morro de São Paulo (Bahia), a embarcação foi surpreendida por uma violenta explosão. Naquele instante estabeleceu-se pânico entre a tripulação e os passageiros, e houve uma correria para as baleeiras. Segundo os relatos da época, essa nau afundou em dez minutos, em meio a ventos fortes e mar agitado. Durante essa tragédia, a tripulação conseguiu se salvar, mas 36 passageiros (civis e militares) acabaram morrendo. O "Vapor Itagiba" pertencia a uma classe de navios que atuavam no serviço de cabotagem e, com isso, transportavam cargas e passageiros. À época do naufrágio, o barco comportava 181 pessoas, entre tripulantes, passageiros e militares ${ }^{3}$.

Em que pese o final trágico do Itagiba nos mares brasileiros, nasce, todavia, um dos mais importantes episódios da história da propaganda brasileira, e esse acontecimento foi um "divisor de águas” que culminou na entrada do país na II Guerra Mundial (Segunda Guerra Mundial).

Neste momento, deparamo-nos, frente ao descrito no trecho anterior, com o processo que transforma um fato em acontecimento histórico e midiático. Para discutir a implicação do que deixa de ser fato para a definição de acontecimento, recuperam-se as ideias de Louis Queré (in FRANÇA e OLIVEIRA, 2012, p.37), também abordado por Alves (2016, p.20), que discutem um acontecimento, no âmbito da comunicação, considerando diferenças entre as definições do primeiro autor sobre acontecimento existencial, de uma ocorrência de um fato percebido na experiência sensível do viver nas várias esferas sociais, e o acontecimento-objeto, cujo investimento simbólico se dá num nível mais profundo que o primeiro tipo, estabelecendo-se nas possibilidades de lógicas de apropriação e no sentido social que tal acontecimento passa a ganhar.

E, nesta parte da história, entra em cena a pequena sobrevivente Walderez Cavalcante e a marca Nestlé. Essa criança, de quatro anos de idade, que viajava com o pai e que se perde na tragédia, ficou três horas após o naufrágio, sozinha, flutuando no mar do litoral do Estado da Bahia, graças a uma caixa vazia de leite condensado, até acontecer o resgate. A surpreendente história foi retratada pela sobrevivente, setenta (70) anos depois do acontecimento sob forte comoção.

Eu me lembro com muita emoção daquele dia. Era um dia comum na vida de uma menina que viajava junto com o pai que trabalhava no navio. Eu não tinha ideia do que aconteceria, mas às $10 \mathrm{~h} 50$ fomos surpreendidos por uma explosão que gerou um estremecimento geral no navio. Alguém falou 'fomos torpedeados'. Nisso meu pai me pegou e fomos a uma baleeira [usado como barco salva-vidas] do navio, já que ele estava afundando. Mas quando o Itagiba [o navio] afundou, o mastro caiu sobre a

3 http://ultimosegundo.ig.com.br/brasil/2012-08-19/ha-70-anos-os-naufragios-e-o-resgate-que-levaram-o-brasil-a-entrar-na-2guerra.html, acessado em 30/04/2019 
baleeira em que estávamos e atingiu o meu pai, que fraturou a bacia e ficou enrolado aos fios. Foi alguém me colocou dentro da caixa de madeira de leite condensado dizendo "não solte" e fomos todos para água, onde fiquei por cerca de três horas à deriva, quando fui encontrada por uma outra embarcação onde meu pai estava", conta Walderez, hoje com 74 , em entrevista para o iG 4 .

Essa tragédia destacou, entre tantas, a história dessa garota e a inusitada forma pela qual ela conseguiu sobreviver. Há pouca lembrança no imaginário brasileiro de nossa participação nesse conflito e da importância que a imprensa dedicou a essa tragédia no final da década de quarenta (1940). Uma guerra que envolveu tantos países e que reconfigurou a geografia mundial, tratava-se de um conflito distante que acompanhávamos pelos jornais e nos cinejornais transmitidos nas salas de cinema daquela época. De fato, o afundamento do ltagiba foi chamado pela impressa da época de "Pearl Harbor brasileiro", pelo fato de o navio ter sido alvejado por um torpedo do submarino nazista U-507 no litoral nordestino. E essa comparação não era nada trivial. Instava-se ao imaginário recente o ataque surpresa contra a base americana que se encontrava estrategicamente localizada no Havaí. Alguns meses antes (dezembro de 1941), havia ocorrido o ataque japonês a "Pearl Harbor", e essa operação aeronaval contra a frota dos Estados Unidos, deflagrada pela Marinha Imperial Japonesa, marcou, de forma definitiva, a participação desses países na Segunda Guerra Mundial! 5 .

Da mesma forma que aconteceu nos Estados Unidos da América (EUA) em relação ao Japão, o clamor das ruas brasileiras leva o então presidente Getúlio Vargas a declarar apoio aos aliados, e o Brasil passa a participar do esforço de guerra para derrotar os países do eixo (Alemanha, Itália e Japão), juntamente com os norte-americanos, a Inglaterra e a França. Nosso país deixa de ser um mero espectador para atuar como coadjuvante nesse emblemático momento da história internacional. A neutralidade abre espaço para uma participação efetiva nesse confronto, seja por exigência da sociedade e dos interesses econômicos do país, seja pela percepção que as grandes nações tinham de que essa suposta indefinição poderia mascarar outras questões. Suspeitava-se que o Presidente Getúlio Vargas nutria uma certa admiração pelo regime fascista, e esse sentimento poderia levar-nos a um alinhamento com os países do eixo (Alemanha e, principalmente, Itália) (MOURA, 2012, p. 81-83). O Brasil encontrava-se em pleno regime

\footnotetext{
${ }^{4}$ ANDRADE, Miguel. Vida de menininha salva pelo Leite Moça. In http://cidadaoquem.blogspot.com.br/2012/08/vida-de-menininhasalva-pelo-leite-moca.html, acessado em 30/04/2019.

${ }_{5}^{5}$ MONTEIRO, Marcelo. Pearl Harbor no Brasil, In https://super.abril.com.br/historia/pearl-harbor-no-brasil/, acessado em 30/04/2019
} 


\section{ALCEU

denominado de "Estado Novo", que se caracterizou por uma constituição que reforçava um estado centralizado e antiliberal. Mas os acontecimentos históricos internacionais vão se sobrepor ao projeto de poder local da época. E o naufrágio do Itagiba insere-se nesse contexto global.

A figura 1 destaca a manchete do Jornal O Globo da época, destacando o torpedeamento do vapor brasileiro.

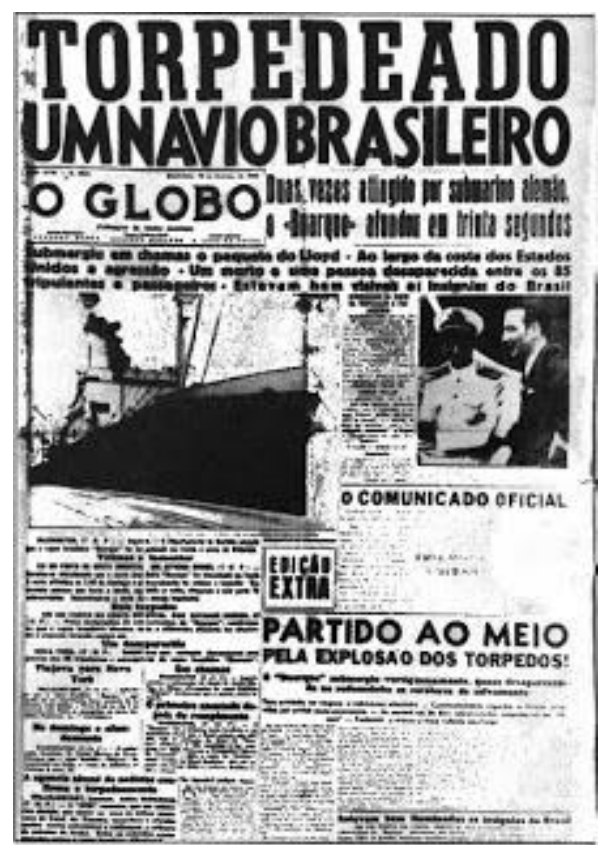

Figura 1 - Manchete do Jornal "O Globo"

Fonte: http://cidadaoquem.blogspot.com.br/2012/08/vida-de-menininha-salva-pelo-leite-moca.html, acesso 02/05/2019.

O ataque a essa fragata brasileira, de fato, não pode ser considerado um episódio isolado. Tinha-se suspeita que, desde fevereiro de 1942, submarinos alemães e italianos estavam torpedeando embarcações nacionais em represália ao acordo que assumimos na denominada "Carta do Atlântico" - o compromisso de "alinhamento automático com qualquer nação do continente americano que fosse atacada por uma potência extracontinental". (MOURA, 2012, p. 81 89; MONTEIRO, 2012).

A grande pressão popular para que o Brasil apoiasse os aliados fez com que Vargas fosse compelido a pactuar com os americanos a nossa participação na II Guerra Mundial. A sucessão de ataques às embarcações do país e, particularmente, ao navio Itagiba, selaria a nossa atuação nessa guerra. Nesse cenário, insere-se a comovente e impressionante história que fez da pequena Walderez Cavalcante uma celebridade, salva do naufrágio, graças a um caixote que transportava 
o produto "Leite Moça", e que funcionou como uma espécie de bote salva-vidas. Na época, esse acontecimento fantástico motivou a empresa a fazer uma campanha e/ou ação publicitária institucional que envolveu a entrega de uma boneca e uma quantia significativa, no valor de um conto de réis, como presente para nossa criança-heroína. Aqui se instaura um acontecimentoobjeto publicitário, com alta potencialidade de apropriação pelo público para gerar empatia com a

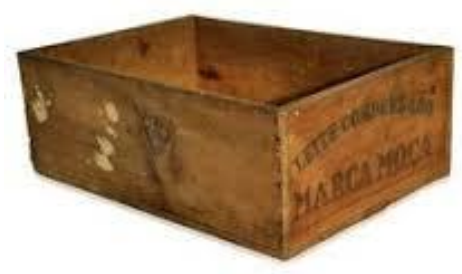

marca Nestlé, pelo seu valor simbólico.

Figura 2 - Foto ilustrativa de uma caixa de madeira para o transporte do produto Nestlé nos anos 1950 Fonte: https://i.pinimg.com/236x/0e/64/5c/0e645c4b8d97a9e503892107d261648b--wood-boxes-tempo.jpg, acesso 30/04/2019

A comparação entre os acontecimentos existenciais (o ataque a Pearl Harbor e o ataque ao Itagiba, sendo este equiparado pela mídia da época como Pearl Harbor brasileiro) pode ser considerada o primeiro nível de investimento simbólico que possibilita à marca Nestlé configurar e explorar esse acontecimento-objeto. Ao se apropriar do fato de que a menina sobreviveu ao naufrágio por causa de uma "caixa de Leite Moça", a empresa Nestlé conseguiu uma das mais impressionantes narrativas para o imaginário da época 4 .

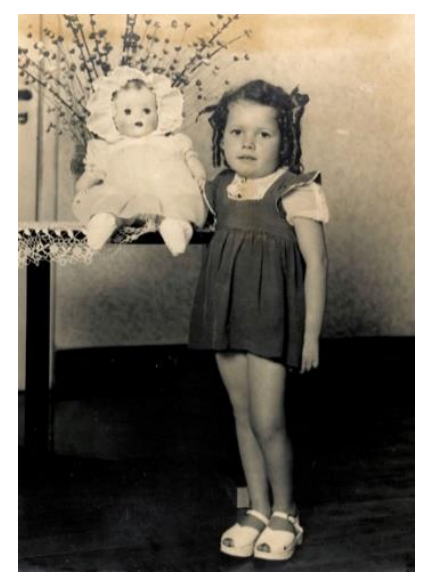

Figura 3 - Foto da menina salva pela caixa do produto Leite Moça 


\section{ALCEU}

Fonte: http://cidadaoquem.blogspot.com.br/2012/08/vida-de-menininha-salva-pelo-leite-moca.html, acessado em 30/04/2019

A tragédia dessa garota ganhou a mídia massiva da época, circulando nos cinejornais, revistas e jornais impressos que narravam a desventura da garota e como a caixa de madeira que acondicionava os produtos Nestlé foi fundamental para a sua sobrevivência. Foi com essas estratégias midiáticas que a marca publicizou, promoveu sua mensagem publicitária e institucionalizou positivamente sua imagem junto ao público brasileiro.

\section{A institucionalidade, mediações, midiatização e memória organizacional}

O relato anterior nos coloca frente à problemática comunicacional em relação à possibilidade de estudos que se referem ao uso de fatos da realidade para a espetacularização, promoção e institucionalização no ambiente social de ação das organizações, marcas, produtos e serviços para com seus públicos. No caso deste trabalho, abordaremos a marca Nestlé, permitindo, desse modo, a construção de relevantes conceitos para compreensão das estratégias das marcas em suas ações no mercado global e em contextos específicos.

Isso quer dizer que, a serviço da economia global midiatizada, a comunicação das marcas passa a se utilizar de acontecimentos históricos e as narrativas revelam-se elementos propulsores da lógica econômica na vida cotidiana, estabelecendo pertinência aos contextos de atuação, trabalhando as mediações do sentido institucional da marca e a mediação da memória de marca ou organizacional para a construção de vínculos com seus públicos no ambiente social que também é o mercado (FREITAS e TRINDADE, 2016).

Ao destrincharmos o parágrafo anterior, esclarecemos que a economia midiatizada tem sido uma dimensão de pesquisa, que se sustenta no pressuposto de que as ações transformadoras das mídias na vida cultural, social (Midiatização), entendendo também as marcas como mídias (TRINDADE e PEREZ, 2016), só se viabilizam economicamente por uma condição comunicacional que as institui no ambiente social, econômico e cultural.

O conceito de midiatização nos auxilia a compreender que a comunicação institui, por meio de uma lógica-mídia na vida cotidiana, e se sobrepõe a outras lógicas institucionais da vida social, como uma espécie supra-institucionalidade da realidade social. Seríamos seres ou sociedades subordinados a uma lógica das mídias, nesse caso das mídias e/ou marcas. Instituímos grande 


\section{ALCEU}

parte do sentido das nossas vidas sob a égide de padrões de marcas. Sobre o conceito de midiatização em uma concepção institucionalistas, nos respaldamos no trabalho de Stig Hjarvard (2013).

Nesse sentido, a institucionalização dos valores das organizações, marcas, produtos e serviços serve à própria institucionalização das práticas econômicas. Nestlé, ao buscar reputação, empatia com seus públicos, estabelece formas de sociabilidade que dialogam com os padrões culturais dos contextos de sua atuação. Esse modo de sociabilidade da marca com o consumidorpúblico se dá na ritualização do consumo midiático que gera apropriações de sentidos. Ou seja, o consumo de mensagens, informações midiáticas sobre um acontecimento, propicia uma adesão, rejeição ou negociação quanto ao objeto-assunto comunicado. Aqui, estamos nos referindo à aplicação empírica do mapa das mediações comunicacionais de Martín-Barbero (2001, p.16), quando o autor defende em seu modelo teórico da comunicação que a vivência sincrônica dos sujeitos em seus contextos culturais (Matriz cultural) no contato com as mídias (formatos industriais) cria uma via de mão dupla em que se podem perceber os modos de presença e ação da comunicação na vida social cultural. Mas, para tanto, é preciso olhar esse fluxo pelo viés diacrônico da lógica da produção com suas técnicas e tecnicidades, em suas ações institucionais em contraposição às lógicas do consumo com suas ritualidades, condições cognitivas e de sociabilidade, percebendo as adesões, resistências e negociações desse consumo, em um dado tempo e espaço (contextos).

O caso apresentado mostra a ação institucional de mercado da Nestlé, que se plasmou pelo acontecimento histórico da entrada do nosso país na Segunda Guerra Mundial, pelos episódios dos cinco ataques aos navios brasileiros, a partir do fato de que uma criança havia se salvado por agarrar-se a uma caixa com a "marca de Leite Moça", em um desses ataques.

Nesse momento, a empresa percebe o potencial de expansão de sua imagem e da possibilidade de institucionalizar-se midiaticamente promovendo esse fato e presenteando a garota de forma amplamente publicizada pela imprensa da época. Essa circulação simbólica cria condições de pertencimento da marca à vida do público pelo seu papel assistencial e de salvadora, numa época marcada por ameaças de violência causadas pela Guerra, permitindo a construção de um fato publicitário que passa a constituir a memória da marca e da organização, bem como insere, em um certo sentido, essa marca na história brasileira, ao associar o produto como partícipe do salvamento desta pequena criança do nosso país. 


\section{ALCEU

Não se trata da promoção de produtos Nestlé, mas sim de promover e/ou institucionalizar a marca como aquela que protege, salva e alimenta o brasileiro, isto é, imprime no imaginário, nas memórias individuais e coletivas, no sentido conceitual de memória atribuído por Halwwachs (1990, p.53) e Le Goff (1990, p.45), os vínculos de confiabilidade e pertencimento dessa marca aos valores nacionais.

Neste ponto, destacamos as contribuições conceituais de Paulo Nassar $(2004$; 2015) ao trabalhar, junto com sua equipe de pesquisa, a ideia de memória nas organizações e narrativas organizacionais, pois esse objeto auxilia a perceber que economia é midiatizada pela colonização do imaginário social pela adesão às narrativas de marcas das organizações, bem como de sua compreensão em/sobre questões referentes à memória das marcas e às narrativas marcárias como lugares de dimensão estratégica no campo da lógica financeira que merecem nossa atenção.

\section{A economia midiatizada de marcas globais:}

\section{Conexões com história, memória de marcas}

A reflexão, a partir do acontecimento comunicacional apresentado, mostra que as dimensões da cultura estão plasmadas pela dimensão econômica, conexão já apresentada em obras consagradas de Fernand Braudel e Michel De Certeau. A análise histórica realizada por intermédio das categorias de memória (individuais, coletivas e do cotidiano) fortalece nosso pressuposto de trabalho sobre a economia midiatizada, mostrando como a lógica do macro se faz impregnar no micro.

As narrativas constitutivas das memórias e imaginários sociais alimentam os processos culturais, ressignificando a história, desde o período em que os mitos eram as principais narrativas, para instituir as lógicas de um devir em um dado sistema produtivo nas sociedades, bem como nos seus consumos.

Nestlé e a pequena Walderez salva por boiar num "caixote de Leite Moça" durante o naufrágio do navio Itagiba, bombardeado no contexto da Segunda Guerra Mundial, criam a narrativa épica capaz de situar a marca em sintonia com o público brasileiro, pois todo país queria se preservar, proteger-se da guerra, e a Nestlé, ao se colocar como um Deus Mitológico, que salvou a criança, protegeu o Brasil, possibilitando nutrir o arquivo de sua memória institucional, por meio da ação publicitária ou do acontecimento-objeto que propiciou à marca seu caráter épico- 
mítico na sua institucionalização, sem rejeições ou negociações, mostrando o seu lugar no nosso país em acordo com seus propósitos de expansão global. Cabe destacar que cada contexto exigirá esforços de pertinência e oportunidades de ocorrências com potencial comunicacional que gerem vínculos e possibilitem a permanente expansão global da marca e a circulação de seus sentidos.

Surge, aqui, um elemento teórico próprio da regionalidade teórica da comunicação (HALL, 2016), que se refere ao fato de que os estudos da economia midiatizadas de marcas caminham em conexão com os estudos de uma história comunicacional sobre memórias de marcas e experiências com as marcas, por parte dos consumidores. Esses estudos da história comunicacional sobre memórias servem à compreensão de uma produção social de sentido que possa compreender o modo do ser/parecer das culturas em suas adesões, negociações e rejeições às lógicas do sistema produtivo nos seus embates com as lógicas do consumo. Nestlé, neste acontecimento publicitário estudado, conquistou total adesão do público. O fato é memorável e compõe um clássico das narrativas da marca no mundo, e a tragédia brasileira proporcionou um papel simbólico e singular da marca Nestlé na história da II Guerra Mundial.

Adriana G. Freitas

Professora titular de Administração de Empresas, PUC-SP Doutora em Política Científica e Tecnológica, UNICAMP

Eneus Trindade Barreto Filho Professor da Escola de Comunicações e Artes, USP Doutorado em Ciências da Comunicação, USP

Recebido em: 02 de dezembro de 2018

Aprovado em: 28 de fevereiro de 2019

\section{Referências bibliográficas}

ALVES, Maria Cristina Dias. Mediações e os dispositivos dos processos criativos da publicidade midiatizada: vestígios e perspectivas. São Paulo: PPGCOM/USP.2016. Tese de doutorado.

ANDRADE, Miguel. Vida de menininha salva pelo Leite Moça. In

http://cidadaoquem.blogspot.com.br/2012/08/vida-de-menininha-salva-pelo-leite-moca.html, acessado em 19/03/2018. 
BRASIL na Segunda Guerra Mundial.

https://brasilnasegundaguerra.webnode.com.br/inicio/, acessado em 19/03/2018.

FREITAS, Adriana Gomes; TRINDADE, Eneus. A economia e o consumo midiatizado das marcas de alimentos e bebidas globais: algumas considerações. Communicare. São Paulo: Faculdade Cásper Llbero, v. 16, n.2. p. 210-228, 2016.

HJARVARD, Stig. The mediatization of culture and society. London, New York: Routledge, 2013.

HALL, Stuart. Ideologia e teoria da comunicação. MatriZes. revista do Programa de Pós-graduação da USP. São Paulo: PPGCOM/USP, v. 10, n.3. 2016, Pp 33-46.

http://www.revistas.usp.br/matrizes/article/view/124648/121876 Acesso em 27/10/2017

HALBWACHAS, Maurice. A Memória coletiva. Rio de janeiro: Paz Terra. 1990.

ITAGIBA (navio).https://pt.wikipedia.org/wiki/Navios brasileiros afundados na Segunda Guerra Mundial, acessado em 19/03/2018

LE GOFF, Jacques. História e Memória. Caminas: UNICAMP. 1990

QUERÉ, Louis. A dupla vida do acontecimento: por um realismo pragmatista. In FRANÇA, Vera.;

OLIVEIRA, Luciana de (Orgs.) Acontecimentos: reverberações. Belo Horizonte: Autêntica, 2012.

MARTÍN-BARBERO, Jesus. Dos meios às mediações. Comunicação, Cultura e hegemonia. 2ed. Rio de Janeiro: Ed.UFRJ. 2001.

MONTEIRO, Marcelo. Pearl Harbor no Brasil, In https://super.abril.com.br/historia/pearl-harbor-no-brasil/, acessado em 19/03/2018

2012.

U-507 - O submarino que afundou o Brasil na Segunda Guerra Mundial. São Paulo: SCHOBA.

Walderez é uma sobrevivente do naufrágio que jogou o país na Segunda Guerra. In

http://blogdonassifblogspotcom.blogspot.com.br/2011/04/walderez-e-uma-sobrevivente-do.html, acessado em 20/03/2018.

MOURA, Gerson. Relações exteriores do Brasil - 1939-1945: mudanças na natureza das relações Brasil-Estados Unidos durante e após a Segunda Guerra Mundial. Brasília: FUNAG. 2012. http://funag.gov.br/loja/download/998-Relacoes Exteriores do Brasil.pdf acessado em 16/03/2018.

NASSAR, Paulo (Org.). 1 Congresso internacional de novas narrativas: encontro de narrativas de comunicações e artes. 1. ed. São Paulo: ECA/USP, 2015. v. 1. 1133p. 


\section{ALCEU \\ Revista de commicacao, cultura e politica}

NASSAR, Paulo (Org.). Memória de Empresa. 1. ed. São Paulo: Aberje Editorial, 2004. v. 1. 126p. TRINDADE, Eneus; PEREZ, Clotilde. Consumo midiáticos e consumo midiatizado: aproximações e diferenças. Uma contribuição teórico-metodológica. In: LUVIZOTTO, Caroline Kraus; LOSNAK, Célio José; ROTHBERG, Danilo (Org.). Mídia e Sociedade em transformação. 1ed.São Paulo: Cultura Acadêmica, 2016, v. 1, p. 13-27.

\section{Resumo}

O objetivo deste artigo é discutir o papel da memória e da história na lógica econômica e midiatizadora das organizações em processos de expansões globais de suas marcas. Observa-se, a partir do acontecimento do naufrágio do Vapor Itagiba no Brasil durante a Segunda Guerra Mundial, a perspectiva de tratamento da construção de sentidos do acontecimento-objeto, referente ao fato histórico e sua transformação em acontecimento midiático/comunicacional, frente às ações de institucionalização e promoção da marca Nestlé no Brasil. Para tanto, apresenta-se o fato histórico, como acontecimento e os usos midiáticos desta ocorrência em benefício da ação institucional e promoção da memória organizacional da marca Nestlé em sua ação de expansão no contexto brasileiro. O texto finaliza ressaltando os aspectos teóricos e metodológicos para os estudos de midiatização das marcas na ação da construção das institucionalidades e das memórias organizacionais nas culturas, como possibilidade de estabelecer vínculos com os vários públicos das organizações em seus processos de expansão em vários mercados de consumo.

Palavras-chave: Economia midiatizada; Marca; Institucionalidade; Memória; Comunicação organizacional.

\section{Abstract}

This article aims to discuss the role of memory and history in economic logic and mediation of organizations in processes of global expansions, from the event of the Itagiba Vapor wreck on the During II World War, with atention to institutionalization and promotion of the Nestlé brand in Brazil. The article begins presenting the historical fact, as an event and the mediatizated uses of this occurrence in favor of institutional action and memory promotion to Nestlé brand in its brazilian expantion. The text ends by highlighting the theoretical and methodological aspects studies on the mediatization of brands in the construction of institutions and organizational memories in cultures, such as possibility of establishing links with the various publics of the organizations in its expansion processes in several consumer markets.

Keywords: Mediatizated economy; brand; institutionality; memory; Organizational communication. 